\title{
Influence of Media Supplementation with Alpha Tocopherol and/or Epigallocatechin Gallate on in vitro Maturation and Subsequent Fertilization of Bovine Oocytes
}

\author{
W.L. Singh ${ }^{1}$, P.M. Barua ${ }^{1}$, and J. Sonowal ${ }^{2 *}$ \\ ${ }^{1}$ Department of Animal Reproduction, Gynaecology and Obstetrics, Assam Agricultural University, Khanapara, INDIA \\ ${ }^{2}$ Division of Veterinary Biotechnology, ICAR-Indian Veterinary Research Institute, Izatnagar, INDIA
}

*Corresponding author: J Sonowal; E-mail: joyshikh@gmail.com

Received: 31 Aug., 2019

Revised: 10 Oct., 2019

Accepted: 15 Oct., 2019

\begin{abstract}
The present study was planned to determine the effect of Epigallocatechin Gallate (EGCG), Alpha tocopherol and their combination as an antioxidant in TCM-199 media for in vitro maturation (IVM) and in vitro fertilization (IVF) in bovine oocytes. Cumulus-oocyte complexes (COCs) were aspirated from the ovaries derived from slaughter house and in vitro cultured in three groups using TCM-199 supplemented with EGCG @10 $\mu \mathrm{M}$, Alpha tocopherol @100 $\mu \mathrm{M}$, and Combination (EGCG @ $10 \mu \mathrm{M}$ plus Alpha tocopherol @100 $\mu \mathrm{M}$ ). Oocytes of a control group were matured in TCM-199 medium without any treatment. After IVM, cumulus-free oocytes were co-incubated with frozen-thawed spermatozoa for 15-18 h. Compared to no addition, the presence of EGCG @ $10 \mu \mathrm{M}$ in medium during IVM significantly $(p<0.05)$ increased the proportion of maturation and fertilization rate. Combination produced significantly higher percentage of in vitro matured bovine oocytes compared to the alpha tocopherol @100 $\mu \mathrm{M}$ alone. The results suggest that EGCG @10 $\mu \mathrm{M}$ in IVM medium had better effect than Alpha tocopherol alone and Combination on in vitro maturation and subsequent fertilization of bovine oocytes.
\end{abstract}

Keywords: Alpha tocopherol, Epigallocatechin gallate, IVM, IVF, TCM-199

The production of reactive oxygen species (ROS), as superoxide anion, hydroxyl radical, hydrogen peroxide and lipid peroxides, is a normal process that occurs in the cell when there is a deviation of electrons to oxygen during electron transfer reactions in the mitochondrial respiratory chain and in other intracellular electron transfer systems. Recent studies have shown that ROS are present at low concentrations in the female genital tract, which is beneficial for the sperm-oocyte fertilization process (Lamirande and Lamothe, 2009). However, the atmospheric oxygen concentration during in vitro maturation (IVM) results in excess ROS lead to oxidative stress, which damages DNA, lipids, and proteins, leading to defects and delays in embryonic development (Tsunoda et al., 2014). Oxidative damage to lipids in the oocyte may result in persistently poor oocyte quality after early life exposure to several toxicants as reported by Luderer (2014). Studies have further demonstrated that oxidative stress interferes with oocyte maturation, which may influence early embryonic development, block two-cell embryos in vitro by modifying the key transcription factors, transforming gene expression and eventually resulting in female infertility (Fernandez et al., 2016).

In vitro culture results in higher oxygen tension or concentrations than in vivo environments, which activates various oxidase enzyme systems in the cells and influences generation of oxidative stress (ROS). Polyunsaturated lipids of cellular membranes are very sensitive to peroxidation by ROS. It has been observed that alpha tocopherol, the most active form of Vitamin E, is present in cellular membranes and acts as a protective liposoluble

How to cite this article: Singh, W.L., Barua, P.M. and Sonowal, J. (2019). Influence of media supplementation with alpha tocophero and/or epigallocatechin gallate on in vitro maturation and subsequent fertilization of bovine oocytes. J. Anim. Res., 9(6): 863-868. 
agent against lipoperoxidation by removing peroxyl and alcoxyl radicals, generating the poorly reactive tocopheryl radical (Tao et al., 2010; Arias Alvarez et al., 2018). In mammalian cells, there is an enzymatic antioxidant system (superoxide dismutase, glutathione peroxidase and catalase), which acts as an ROS scavenger, controlling their production to prevent cell damage. Although, cellular injury and death may occurs under the extreme oxidative conditions. Alpha tocopherol, the predominant lipidsoluble antioxidant in animal cells, protects cells from oxygen radicals in vivo and in vitro, and is believed to be the primary free radical scavenger in mammalian cell membranes. Another antioxidant Epigallocatechin gallate (EGCG) is a major ingredient of catechin polyphenols in green tea and is considered to be one of the most bioactive chemical compounds due to its strong antioxidant properties, EGCG has the ability to quench free radical species and chelate transition metals, which contributes to reducing oxidative stress levels (Roychoudhury et al., 2017). These catechins have strong antioxidant activity and effective in enhancing in vitro maturation and fertilization rate and are potent scavengers of ROS (Hu et al., 2011; Barakat et al., 2014).

\section{MATERIALS AND METHODS}

The media and chemicals used to conduct the present study were procured from Sigma-Aldrich, USA.

\section{Collection of ovary and oocytes}

The cattle ovaries were collected from a slaughter house in warmed $\left(37^{\circ} \mathrm{C}\right)$ normal saline solution $(0.9 \%)$ containing Gentamicin $(50 \mu \mathrm{g} / \mathrm{ml})$ in a thermos flask and brought to the laboratory within 2 hours after the animals were slaughtered. The extraneous tissues were removed from the ovaries with the help of scissors. The ovaries were then washed 3-4 times in physiological saline solution containing Gentamicin $(50 \mu \mathrm{g} / \mathrm{ml})$ prior to processing. The oocytes were retrieved using aspiration and slicing technique in aspiration medium (Singh et al., 2018). Only oocytes with at least three layers of compact cumulus cells and homogenous cytoplasm were selected for further processing.

\section{In vitro maturation}

COCs were washed three times each in washing medium
(TCM-199 supplemented with Fetal bovine serum (10\%), sodium pyruvate $(0.8 \mathrm{mM})$, L-glutamine $(0.7 \mathrm{mM})$ and gentamicin sulphate $(50 \mu \mathrm{g} / \mathrm{ml}))$ and in maturation medium (Sonowal et al., 2017) with epigallocatechin gallate concentration $(10 \mu \mathrm{M})$ or Alpha tocopherol $(100 \mu \mathrm{M})$ or Combination of Epigallocatechin gallate $(10 \mu \mathrm{M})$ plus Alpha tocopherol $(100 \mu \mathrm{M})$ and control without treatment. COCs were then incubated in $50 \mu 1$ droplets (8-10 oocytes per drop) of maturation medium. The droplets were covered with mineral oil and then incubated at $38.5^{\circ} \mathrm{C}$ in $5 \% \mathrm{CO}_{2}$ with $90-95 \%$ humidity for $24 \mathrm{~h}$.

\section{In vitro fertilization}

The IVF were carried out as described by Wang et al. (2013). Briefly, matured COCs were washed thrice in washing TALP (Tyrode's Albumin Lactate Pyruvate Solution) and twice in fertilization TALP and then placed in $50 \mu 1$ droplets (10-12 COCs per droplet) of fertilization medium. Frozen bull semen was thawed and prepared by a swim-up procedure. Sperm cells were added to the fertilization drops at a concentration of 2 million per $\mathrm{ml}$. Incubation was carried out at $38.5^{\circ} \mathrm{C}$ in $5 \% \mathrm{CO}_{2}$ with 90 95 per cent humidity for $18 \mathrm{~h}$.

\section{Evaluation of oocytes after IVM and IVF}

After 24 hours of incubation in a $\mathrm{CO}_{2}$ incubator maintaining the temperature at $38.5^{\circ} \mathrm{C}$ with $5 \% \mathrm{CO}_{2}$ in humidified air, oocytes were examined under the Phase contrast inverted Microscope at $40 \times 10 \mathrm{X}$ zoom for assessment of in vitro maturation. Maturation status was assessed based on:

1. Degree of expansion of cumulus cells (Full and moderate) (Fig. 1a).

2. Extrusion of $1^{\text {st }}$ polar body in the perivitelline space (Fig. 1b).

Degree of expansion of cumulus cell expansion was observed as follows:

As a result of in vitro maturation, compact cumulus cell mass changes into a disperse structure which leads to a volumetric expansion of the cumulus oocytes complexes.

1. Full cumulus cell expansion: Expansion of the cumulus cell masses to at least three times its original diameter away from the zonapellucida (ZP). 

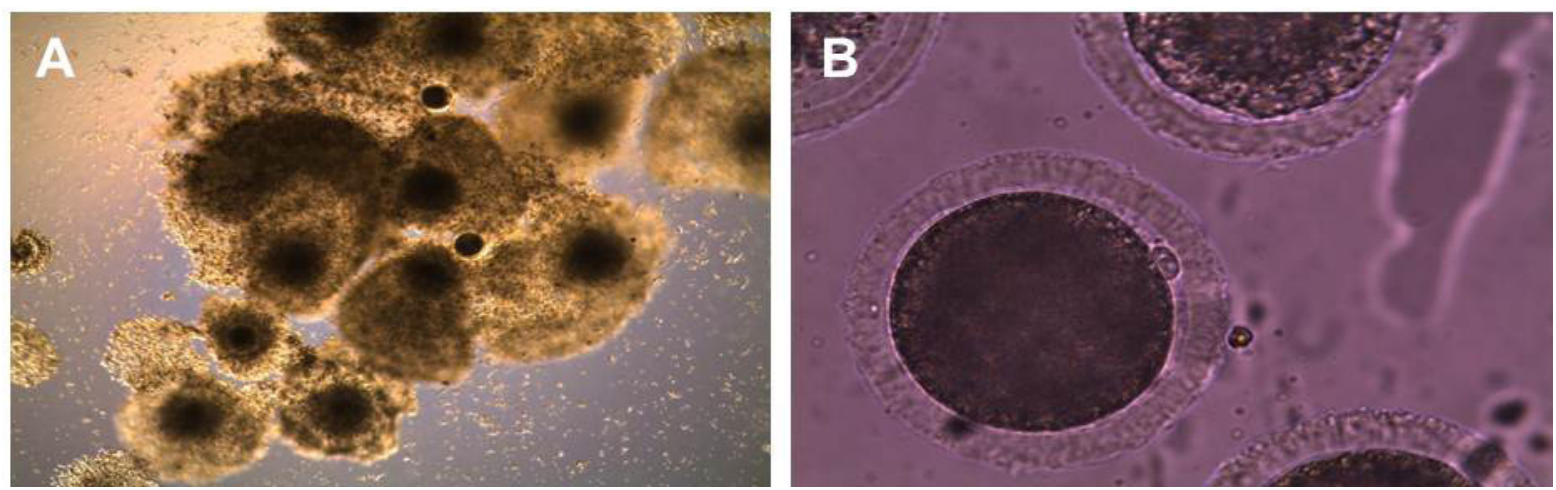

Fig. 1: In vitro matured bovine follicular oocyte showing. (A) Cumulus cells expansion and (B) Extrusion of $1{ }^{\text {st }}$ polar body into perivitelline space
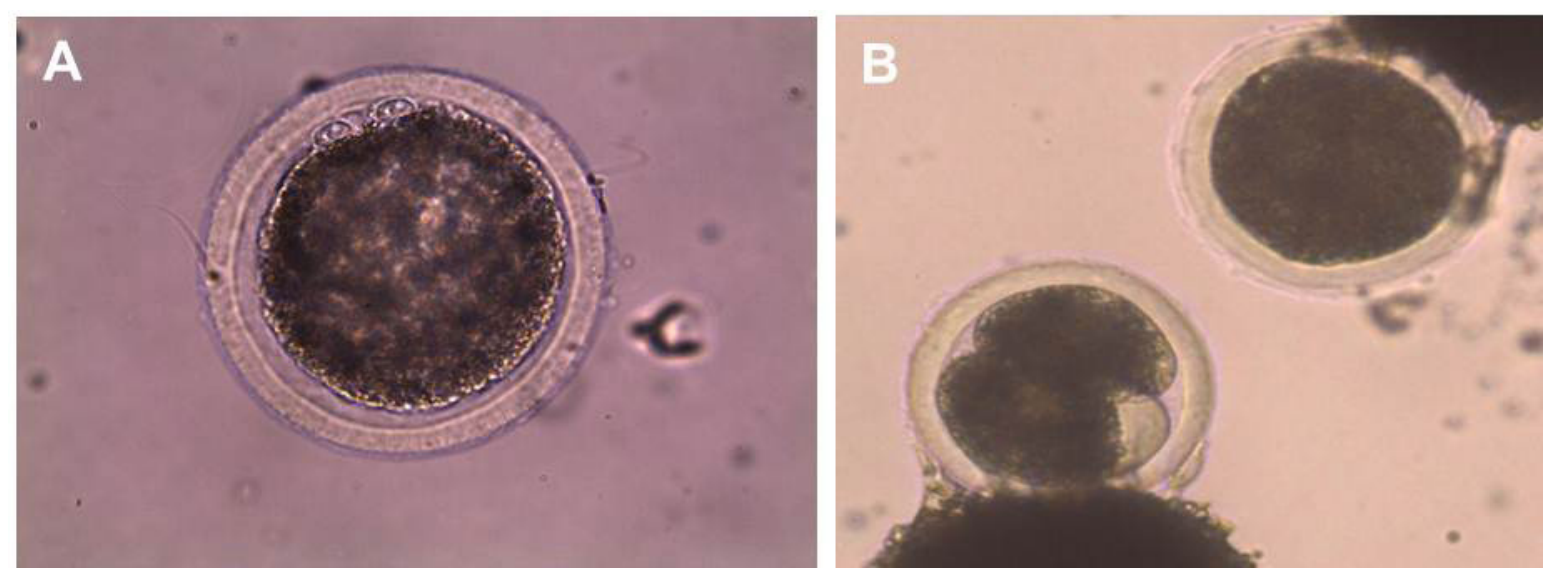

Fig. 2: In vitro fertilized bovine follicular oocyte showing. (A) Extrusion of $2^{\text {nd }}$ polar body into perivitelline space; (B) 2-cell stage oocytes

2. Moderate cumulus expansion: Expansion of the cumulus cell to at least twice its original diameter away from the ZP.

3. Slight or no expansion of the cumulus cell mass: Cumulus cells tightly adhered to the ZP.

After 18 hours of co-culture of sperm and oocytes in a $\mathrm{CO}_{2}$ incubator maintaining the temperature at $38.5^{\circ} \mathrm{C}$ with $5 \%$ $\mathrm{CO}_{2}$ in humidified air, under the Phase contrast inverted Microscope at $40 \times 10 \mathrm{X}$ zoom. Fertilization status was assessed based on: Extrusion of $2^{\text {nd }}$ polar body in the perivitelline space (Fig. 2 a \& b).

\section{Statistical Analysis}

Results obtained were subjected to analysis of variance and treatment means were ranked using Duncan multiple range test. The statistical analysis was done by using SAS enterprise guide 4.3 .

\section{RESULTS AND DISCUSSION}

Effects of Epigallocatechin gallate on the $1^{\text {st }}$ and $2^{\text {nd }}$ polar body extrusion rate

EGCG at given concentration supplemented in medium significantly $(p<0.05)$ enhanced cumulus cell expansion, $1^{\text {st }}$ polar body and $2^{\text {nd }}$ polar body extrusion of bovine follicular oocytes than other supplementation and control (Table 1). Supporting the present finding (Huang et al., 2018) addition of EGCG during IVM culture efficiently improves both nuclear and cytoplasmic maturation of bovine oocytes and subsequent developmental competence 
Table 1: In vitro Maturation and fertilization rate of Bovine Oocytes based on Cumulus cell expansion, $1^{\text {st }}$ Polar body and $2^{\text {nd }}$ Polar body extrusion in TCM-199 based medium containing different concentration of antioxidant

\begin{tabular}{|c|c|c|c|c|c|c|c|c|}
\hline \multirow[b]{2}{*}{ Antioxidant } & \multirow{2}{*}{$\begin{array}{c}\text { No. of } \\
\text { oocytes } \\
\text { used for } \\
\text { IVM }\end{array}$} & \multicolumn{2}{|c|}{ Cumulus Cell Expansion } & \multicolumn{2}{|c|}{$1^{\text {st }}$ Polar body extrusion } & \multicolumn{3}{|c|}{$2^{\text {nd }}$ Polar body extrusion } \\
\hline & & $\begin{array}{c}\text { No. of } \\
\text { oocytes } \\
\text { matured }\end{array}$ & $\begin{array}{c}\text { IVM \% } \\
(\text { Mean } \pm \text { SE) }\end{array}$ & $\begin{array}{c}\text { No. of } \\
\text { oocytes } \\
\text { matured }\end{array}$ & $\begin{array}{c}\text { IVM \% } \\
(\text { Mean } \pm \text { SE) }\end{array}$ & $\begin{array}{l}\text { No. of matured } \\
\text { oocytes use for } \\
\text { IVF }\end{array}$ & $\begin{array}{c}\text { No. of } \\
\text { Fertilized } \\
\text { oocytes }\end{array}$ & $\begin{array}{c}\text { IVF \% } \\
(\text { Mean } \pm \text { SE) }\end{array}$ \\
\hline Vitamin E $(100 \mu \mathrm{M})$ & 298 & 184 & $62.22^{\mathrm{b}} \pm 2.26$ & 139 & $46.88^{c} \pm 1.58$ & 139 & 55 & $40.25^{\mathrm{b}} \pm 2.31$ \\
\hline EGCG $(10 \mu \mathrm{M})$ & 299 & 221 & $74.10^{\mathrm{a}} \pm 1.97$ & 171 & $57.27^{\mathrm{a}} \pm 1.32$ & 171 & 94 & $55.35^{\mathrm{a}} \pm 2.24$ \\
\hline $\begin{array}{l}\text { Vitamin E }(100 \mu \mathrm{M}) \\
+ \text { EGCG }(10 \mu \mathrm{M})\end{array}$ & 300 & 214 & $71.65^{\mathrm{a}} \pm 2.00$ & 154 & $51.70^{\mathrm{b}} \pm 2.18$ & 154 & 67 & $44.07^{b} \pm 2.57$ \\
\hline Control & 274 & 154 & $56.39^{\mathrm{c}} \pm 1.76$ & 124 & $45.27^{\mathrm{c}} \pm 1.73$ & 124 & 51 & $41.82^{\mathrm{b}} \pm 2.21$ \\
\hline
\end{tabular}

Means with the different superscripts in a column differ significantly $(p<0.05)$.

of embryos. GTP(Green tea polyphenols)@15 $\mu \mathrm{M}$ during IVM and IVC significantly enhanced in vitro maturation rate and subsequent post cleavage development to the blastocyst stage in bovine oocytes (Wang et al., 2013). Barakat et al. (2014) also reported that GTE (Green tea extract) at concentrations of $0.3 \mathrm{mg} / \mathrm{ml}$ in IVM medium enhanced the in vitro maturation and embryo development of sheep oocytes to blastocyst stage. However, at higher dose $(200 \mu \mathrm{g} / \mathrm{ml})$ of GTE (Roychoudhury et al., 2018) apoptosis is markedly increased than lower dose $(0.1,1,10$ and $100 \mu \mathrm{g} / \mathrm{ml}$ ) which is due to the increase accumulation of caspase-3 and p53 apoptotic markers in granulosa cells of Porcine. So, Epigallocatechin gallate has the similar effect of GTP and GTE at lower concentration and effective in increasing rate of in vitro culture of oocytes.

\section{Effects of alpha tocopherol on the $1^{\text {st }}$ and $2^{\text {nd }}$ polar body extrusion rate}

Alpha tocopherol @100 $\mu \mathrm{M}$ supplemention does not increase the success rates. Supporting with our observations, addition of alpha-tocopherol to the maturation medium failed to significantly improve the in vitro maturation and in vitro fertilization rate in porcine (Tao et al., 2010) and ovine (Adeldust et al., 2015) and was detrimental to the bovine embryo development Marques et al. (2010) and Sudano et al. (2010). Irrespective of the environmental oxygen concentration alpha tocopherol supplementation did not cause any significant change to the rate of oocyte maturation and embryo formation and development (Natarajan et al., 2010). However, Contrary to the present findings Thiyagarajan and Valivittan, (2009) and Sonowal et al. (2017) reported that alpha-tocopherol (a) $100 \mu \mathrm{M}$ supplementation on in vitro maturation media significantly enhanced the rate of maturation. Arias Alvarez et al. (2018) also reported similar finding in rabbit with addition of @ $100 \mu \mathrm{M}$ alpha-tocopherol to the maturation medium as suitable approach to manage oxidative stress and apoptosis, as well as for increasing the in vitro developmental competence. This discrepancy in various studies might be due to variation in the breeds and species of the animals used, presence of cumulus cells, quality of the oocytes and the composition of culture medium used.

Effects of Epigallocatechin gallate and Alpha tocopherol combination on the $1^{\text {st }}$ and $2^{\text {nd }}$ polar body extrusion rate

Combination of Antioxidants (EGCG@10 $\mu \mathrm{M}$ plus alpha tocopherol @100 $\mu \mathrm{M})$ shows significantly $(p<0.05)$ higher success rates than alpha tocopherol alone and control (Table 1). Supporting the present finding Chu et al. (2017) and Hussain et al. (2018) reported that GTP has two different actions: an antioxidant action at lower, and a pro-oxidant action at higher concentrations. So, possible reason would be the addition of two potent antioxidant resulted in alteration of antioxidant to pro-oxidant effect that might hampered its action or two antioxidants might not have synergistic effect Goncalves et al. (2010) and Sudano et al. (2010) that failed to significantly improve in vitro maturation rate and subsequent fertilization. However, additional details will be required to ascertain the exact mechanism involved in this process. 


\section{CONCLUSION}

The results of this study help to better understand that addition of EGCG@10 $\mu \mathrm{M}$ significantly enhanced in vitro maturation and subsequent fertilization. Combination (known concentrations) also produced significantly higher percentage as compared to the use of Alpha tocopherol alone. Although the antioxidant properties of alpha tocopherol are well known, but in our observation EGCG at known concentration is found to be superior than rest of the supplementation in improving rate of in vitro culture.

\section{ACKNOWLEDGEMENTS}

The authors are thankful to the department of Animal Reproduction, Gynaecology and Obstetrics, College of Veterinary Science, AAU, Guwahati, India-781022 for technical supports and the laboratory facilities.

\section{REFERENCES}

Adeldust, H., Zeinoaldini, S., Kohram, H., Roudbar, M.A. and Joupari, M.D. 2015. In vitro maturation of ovine oocyte in a modified granulosa cells co-culture system and alphatocopherol supplementation: effects on nuclear maturation and cleavage. J Anim. Sci. Technol., 57(27): 1-6.

Arias Alvarez, M., Garcia Garcia, R.M., Lopez Tello, J., Rebollar, P.G., GutirrezAdan, A. and Lorenzo, P.L. 2018. $\alpha$-Tocopherol modifies the expression of genes related to oxidative stress and apoptosis during invitro maturation and enhances the developmental competence of rabbit oocytes. Reprod.Fertil. Dev., 30(12): 1728-1738.

Barakat, I.A.H., Al-Himaidi, A.R. and Rady, A.M. 2014. Antioxidant Effect of Green Tea Leaves Extract on in vitro Production of Sheep Embryos. Pak. J. Zool., 46(1): 167-175.

Chu, C., Deng, J., Man, Y. and Qu, Y. 2017. Green Tea Extracts Epigallocatechin-3-gallate for Different Treatments. BioMed. Res. Int., 1-9.

Fernandez, R.G., Hernandez, J., Vasallo, P.M., Puopolo, M., Palumbo, A. and Avila, J. 2016. Expression levels of the oxidative stress response gene ALDH3A2 in granulosalutein cells are related to female age and infertility diagnosis. Reprod. Sci., 23(5): 604-609.

Goncalves, F.S., Barretto, L.S.S., Arruda, R.P., Perri, S.H.V. and Mingoti, G.Z. 2010. Effect of Antioxidants During Bovine in vitro Fertilization Procedures on Spermatozoa and Embryo Development. Reprod. Dom.Anim., 45: 129-135.

Hu, Y., Guo, D.H., Liu, P., Cao, J.J., Wang, Y.P., Yin, J., Zhu, Y. and Rahman, K. 2011. Bioactive components from the tea polyphenols influence on endogenous antioxidant defense system and modulate inflammatory cytokines after total-body irradiation in mice. Phytomedicine, 18(11): 970-975.

Huang, Z., Pang, Y., Hao, H., Du, W., Zhao, X. and Zhu, H. 2018. Effects of epigallocatechin-3-gallate on bovine oocytes matured in vitro. Asian-Aust. J Anim. Sci., 31(9): 1420-1430.

Hussain, S. and Ashafaq, M. 2018. Epigallocatechin-3-Gallate (EGCG): mechanisms, perspectives and clinical applications in cervical cancer. J Canc. Prev. Curr. Res., 9(4): 178-182.

Lamirande, E. de and Lamothe, G. 2009. Reactive oxygeninduced reactive oxygen formation during human sperm capacitation. Free Radic. Biol. Med., 46(4): 502-510.

Luderer, U. 2014. Ovarian toxicity from reactive oxygen species. Vitam. Horm., 94: 99-127.

Marques, A., Santos, P., Antunes, G.,Chaveiro, A.and Moreira da Silva, F. 2010. Effect of $\alpha$-Tocopherol on Bovine In vitro Fertilization. Reprod. Dom. Anim., 45: 81-85.

Natarajan, R.; Shankar, M.B. and Munuswamy, D. 2010. Effect of $\alpha$-tocopherol supplementation on in vitro maturation of sheep oocytes and in vitro development of preimplantation sheep embryos to the blastocyst stage. J Assist. Reprod. Gen., 27(8): 483-490.

Roychoudhury, S., Agarwal, A., Virk, G. and Cho, C.L. 2017. Potential role of green tea catechins in the management of oxidative stress-associated infertility. Reprod. BioMed. Online, 34(5): 487-498.

Roychoudhury, S., Halenar, M., Michalcova, K., Nath, S., Kacaniova, M. and Kolesarova, A. 2018. Green tea extract affects porcine ovarian cell apoptosis. Reprod. Biol., 18(1): 94-98.

Singh, W.L., Barua, P.M., Sonowal, J., Nath, K.C., Borah, P., Borah, R.S., Das, A., Mahanta, D., Das, R. and Malla, W.S. 2018. Antioxidant effect of Epigallocatechingallate on bovine IVM and IVF. J. Entomol. Zool. Stud., 6(4): 401-403.

Sonowal, J., Barua, P.M., Borah, P., Das, A., Deuri, N.K., Dutta, D.J., Sharma, R.K., Choudhury, M.D. and Kalita, D.J. 2017. Effect of antioxidant on in vitro maturation of vitrified bovine oocytes. Indian J Anim. Sci., 87(12): 1477-1479.

Sudano, M.J.,Mattos, M.C.C., Fernandes, C.B.,Mazieiro, R.R. and Landim-Alvarenga, F.C. 2010. In vitro production of bovine embryos using Sigma antioxidant supplement, $\alpha$-tocopherol and L-ascorbic acid. Anim.Reprod. Sci., 7(1): 42-48.

Tao, Y., Chen, H., Tian, N., Huo, D., Li, G., Zhang, Y., Liu, Y., Fang, F., Ding, J., and Zhang, X. 2010. Effects of L-ascorbic acid, $\alpha$-tocopherol and co-culture on in vitro developmental potential of porcine cumulus cells free oocytes. Reprod. Domest. Anim., 45(1): 19-25. 
Thiyagarajan, B. and Valivittan, K. 2009. Ameliorating effect of Alpha tocopherol on in vitro development of pre-implantation buffalo embryos. J Assist. Reprod. Gen., 26: 217-225.

Tsunoda, S., Kimura, N. and Fujji, J. 2014. Oxidative stress and redox regulation of gametogenesis, fertilization and embryonic devlopment. Reprod. Med. Biol., 3(2): 71-79.
Wang, Z.G., Fu, C. and Yu, S. 2013. Green tea polyphenols added to IVM and IVC media affect transcript abundance, apoptosis, and pregnancy rates in bovine embryos. Theriogenology, 79: 186-192. 